\title{
MAKAR DALAM HUKUM PIDANA ISLAM
}

Oleh:

\author{
Hj. Lilies Anisah,SH.,MH
}

(Dosen Tetap Fakultas Hukum Universitas Muhammadiyah Palermbang)

\begin{abstract}
ABSTRAK
Menurut A. Hasjmy, ada tiga dasar untuk menyelenggarakan pemerintahan, yaitu: keadilan pemerintah, ketaatan rakyat, musyawarah antara pemerintah dengan rakyat. Pemerintahan yang baik dimanapun bahkan sampai kapanpun akan tetap ada yang tidak sejalan dengan kebijakan-kebijakan yang telah dibuat pemerintah, bahkan zaman Rasulullah pun telah terjadi makar atau dalam bahasa Arab disebut dengan Al-Bahgyu. Bagaimana Sanksi Hukum Tindakan Makar Dalam Hukum Pidana Islam yang bersumber Al-Quran dan Hadis? metode penelitian yuridis-normatif.

Sanksi hukum bagi pelaku tindak pidana pemberontakan adalah hukuman mati, sebagaimana dijelaskan dalam Al-quran dan hadis Rasulullah SAW, antara lain:Qs. AlHujurat:9 "Dan kalau ada dua golongan dari mereka yang beriman itu berperang hendaklah kamu damaikan antara keduanya. Akan tetapi, kalau yang satu melanggar perjanjian terhadap yang lain, hendaklah yang melanggar perjanjian itu kamu perangi sampai sampai surut kembali pada perintah Allah. Kalau ia telah surut, damaikanlah antara keduanya menurut keadilan, dan hendaklah kamu berlaku adil; sesungguhnya Allah mencintai orangorang yang berlaku adil.” (QS. Al-Hujurat (49):9 dan Hadis "dari Aisyah r.a., ia berkata: "barangsiapa memecah belah persatuan kaum muslimin padahal ia telah sepakat untuk memilih satu pemimpin dengan maksud menceraikan umat, maka bunuhlah ia"

Disimpulkan bahwa tindakan makar yang diatur dalam kitab undang-undang hukum pidana dan termasuk dalam jarimah al-baghyu dalam hukum pidana Islam merupakan tindakan yang menyalahi aturan dan melaggar ketentuan karena orang yang melakukan tindakan perlawanan terhadap pemerintah yang sah berarti sama dengan orang yang melawan ketentuan allah SWT.
\end{abstract}

\section{Kata Kunci : Makar, Al-Baghyu, Hukum Pidana Islam}

\begin{abstract}
According to A. Hasjmy, there are three bases for the administration of government, namely: government governance, people's obedience, deliberation between the government and the people. Governments that are manipulated even at any time will still be incompatible with the policies made by the government, even during the time of the Messenger of Allah, there has been treason or in Arabic it is called Al-Bahgyu. What about the legal sanctions for treason in Islamic criminal law originating from the Koran and Hadith? juridical-normative research methods.

Legal sanctions for those who oppose the punishment for rebellion are the death penalty, which is accepted in the Qur'an and the hadith of the Prophet Muhammad, among others: Qs. Al-Hujurat: 9 "And if there are two groups of those who believe, you must make peace between them. However, if the agreement with the other is rejected, it must be the one you reject that you fight until you arrive at the command of God. If it has receded, reconcile
\end{abstract}


according to justice, and bring you to be just; truly God values those who act justly. "(Surah Al-Hujurat (49): 9 and Hadith" from Aisha, he said: "whoever divides the unity of the Muslims even though he has chosen to elect a leader with the intention of divorcing the people, then kill him"legal aid and al-baghyu land law in Islamic crime law is an act that violates the rules and dissolves the provisions because people who act against the government have the same intention as those who oppose the provisions of Allah SWT.

\section{Keywords: Makar, Al-Baghyu, Islamic Criminal Law}

\section{A. Latar Belakang}

Menurut A. Hasjmy, ada tiga dasar untuk menyelenggarakan pemerintahan, yaitu: keadilan pemerintah, ketaatan rakyat, musyawarah antara pemerintah dengan rakyat. ${ }^{10}$

Islam adalah sistem yang sempurna. Di dalamnya terdapat aturan yang mengatur segala bentuk interaksi antar sesama manusia, seperti sistem sosial, ekonomi, politik, dsb. Aturan-aturan semacam ini meniscayakan adanya negara yang akan melaksanakan dan menerapkan aturan-aturan tersebut kepada manusia. Islam telah menetapkan sistem yang khas bagi pemerintahan. Islam juga telah menetapkan sistem yang khas untuk mengelola pemerintahan. Di samping itu, Islam menuntut seluruh hukum syara (Islam) kepada rakyatnya. $^{11}$

Pemerintahan yang baik dimanapun bahkan sampai kapanpun akan tetap ada yang tidak sejalan dengan kebijakan-kebijakan yang telah dibuat pemerintah, bahkan zaman Rasulullah pun telah terjadi makar atau dalam bahasa Arab disebut dengan Al-Bahgyu. Di Indonesia yang mayoritas peduduknya beragama Islam, makar kerap ditemui. Seperti di Kesultanan Demak oleh Aria Penangsang pada 1549 dan Pemberontakan Kuti terhadap Kerajaan Majapahit masa pemerintahan Raja Jayanegara pada 1319.

Pada masa pemerintahan Presiden Soekarno tercatat dalam sejarah pelaku makar pertama kali ialah Daniel Maukar yang dengan mengendarai pesawat tempur sendiri menyerang Istana Negara. Untunglah pada saat itu Presiden Soekarno tidak sedang berada di dalam istana. Daniel Maukar diadili atas tindakan makar terhadap negara dan juga presiden. Dia dijatuhi hukuman mati meski pada akhirnya diampuni dan hanya menjalani sekitar delapan tahun masa pemidanaan.

Belakangan Makar yang dilakukan untuk menggulingkan pemerintahan banyak terjadi diberbagai daerah. Di Indonesia Makar sendiri telah beberapa kali terjadi bahkan sebelum kemerdekaan Republik Indonesia

10 A. Hasjmy, Di Mana Letaknya Negara Islam, Surabaya: Bina Ilmu, 1984, hlm. 83-84

11 www.kompasiana.com/indria.sari, diakses tanggal 5 Desember 2019 
Menurut Hasan al-Banna, Islam menganggap pemerintahan sebagai salah satu dasar sistem sosial yang dibuat untuk manusia. Islam tidak menghendaki kekacauan atau anarkis dan tidak membiarkan satu jamaah tanpa Imam (pemimpin).Jadi orang yang menganggap bahwa Islam tidak memberi penjelasan tentang politik atau politik bukan bidang pembahasannya, maka ia mengkhianati dirinya dan juga mengkhianati Islam. ${ }^{12}$

\section{B. Permasalahan}

Berdasarkan uraian dari latar belakang masalah tersebut di atas, maka yang menjadi permasalahan dalam jurnal ini adalah Bagaimana Sanksi Hukum Tindakan Makar Dalam Hukum Pidana Islam yang bersumber Al-Quran dan Hadis?

\section{Metode Penelitian}

Penelitian ini menggunakan metode penelitian yuridis-normatif, sumber data seluruhnya menggunakan data sekunder yang digunakan oleh penulis dalam penelitian ini adalah bahan hukum primer yang diperoleh melalui kepustakaan seperti undang-undang ITE dan KUHP serta Alquran dan Hadis, serta data sekunder seperti studi pustaka termasuk literature-literatur terkait dengan bahan hukum primer, media massa seperti Koran, majalah, media internet, dan jurnal-jurnal penelitian yang berhubungan dengan penelitian yang di kaji.

\section{Pembahasan}

Jarimah mengenai jinayah perbuatan makar atau al-baghyu telah diatur dalam nash baik Al-Quran maupun sunnah. Selain telah diatur dalam hukum pidana Islam perbuatan ini pun telah dibahas dalam regulasi pemerintahan Indonesia yang biasa disebut dalam Undang-undang sebagai kejahatan terorisme.

Secara etimologis, al-baghyu berasal dari kata Bugha yang berarti menuntut sesuatu. Dikatakan demikian karena pelaku jarimah bersikap takabbur dengan melampaui batas dalam menuntut sesuatu yang bukan haknya. Hal ini disinggung dalam firman Allah berikut : "Dan kalau ada dua golongan dari mereka yang beriman itu berperang hendaklah kamu damaikan antara keduanya. Akan tetapi, kalau yang satu melanggar perjanjian terhadap yang lain, hendaklah yang melanggar perjanjian itu kamu perangi sampai sampai

12 Hasan al-Banna, Majmu'ah Rasa'il al-Imam Syahid Hasan al-Banna, alih bahasa, Su'adi Sa'ad, "Konsep Pembaruan Masyarakat Islam", Jakarta: Media Da'wah, 1986, hlm. 374-375. 
surut kembali pada perintah Allah. Kalau ia telah surut, damaikanlah antara keduanya menurut keadilan, dan hendaklah kamu berlaku adil; sesungguhnya Allah mencintai orangorang yang berlaku adil." (QS. Al-Hujurat (49):9) ${ }^{13}$

Al-baghyu isim mufrad (singular) sedangkan kata jamak (plural)-nya adalah albughat. Menurut 'urf, al-baghyu adalah meminta sesuatu yang tidak halal atau melanggar hak.14 Secara terminologis,al-baghyu adalah sebagai berikut:

1. Menurut Abdul Qadir Audah, al-baghyu adalah tindakan menentang imam (pemimpin) dengan menggunakan kekuatan ${ }^{15}$

2. Menurut Asadullah al-Faruq, al-bughat adalah sekelompok orang yang mempunyai kekuatan dan dengan kekuatannya berusaha keluar dari imam Karen alasan tertentu. Mereka memberontak terhadap Negara, mengumumkan perang terhadap daulah islamiyah, dan menampakkan perlawanan melalui kekuatan senjata ${ }^{16}$

3. Menurut Rahmat Hakim, al-baghyu adalah usaha melawan pemerintah yang sah dengan terang-terangan atau nyata, baik dengan mengangkat senjata maupun tidak mengindahkan ketentuan yang digariskan pemerintah ${ }^{17}$

4. Menurut A. Hanafi, al-baghyu adalah orang yang berusaha mengadakan perubahan terhadap sistem pemerintahan atau menghasilkan penguasa-penguasa Negara dengan jalan kekerasan, atau menyatakan tidak mau tunduk dengan mendasar pada kekuatan $(\text { senjata })^{18}$

5. Asy-Syafi'i, seperti dikutip H.A.Dzajuli, mengatakan, pemberontak adalah orang muslim yang menyalahi iman, dengan cara tidak menaatinya dan melepaskan diri dari iman, menolak kewajiban, yang memiliki kekuatan, argumentasi dan pimpinan ${ }^{19}$

Menurut Imam al-Mawardi tugas-tugas yang harus diemban oleh kepala negara (sebagai kepala pemerintahan) ada sepuluh hal sebagai berikut:

1. Menjaga agama agar tetap berada di atas pokok-pokoknya yang konstan(tetap)dan sesuai pemahaman yang disepakati oleh generasi salaf (terdahulu) umat Islam. Jika muncul pembuat bid'ah atau pembuat kesesatan, ia berkewajiban untuk menjelaskan

13 Nurul Irvan, Masyrofah. Fiqh Jinayah, jakarta: Amzah, 2013, hlm 59

14 Mardani, Hukum Pidana islam, Jakarta:Kencana,2019, hlm 184

15 Ibid $1, \operatorname{hlm} 30$

16 Asadullah al-Faruq, Hukum Pidana dalam Sistem Hukum Islam. Bogor: Ghalia Indonesia, Cet. Ke-

17 Mustofa dan Beni Ahmad Saebani, Hukum Pidana Islam: Fiqh Jinayah, Bandung: Pustaka Setia,

2013, hlm 454

18 Mardani,Op. Cit, 185

19 Rahmat hakim, Hukum Pidana Islam (Fiqh Jinayah), Bandung; Pustaka setia, 2000, hlm. 108 
hujjah(alasan) kebenaran baginya dan menjelaskan pemahaman yang benar kepadanya, serta menuntutnya sesuai dengan hak-hak dan aturan hukum yang ada, sehingga agama terjaga dari kerancuan dan pemahaman yang salah.

2. Menjalankan hukum bagi pihak-pihak yang bertikai dan memutuskan permusuhan antar pihak yang berselisih, sehingga keadilan dapatdirasakan oleh semua orang. Tidak ada orang zalim yang berani berbuat aniaya dan tidak ada orang yang dizalimi yang tidak mampu membela dirinya.

3. Menjaga keamanan masyarakat sehingga manusia dapat hidup tenang dan bepergian dengan aman tanpa takut mengalami penipuan dan ancaman atas diri dan hartanya.

4. Menjalankan hukum had sehingga larangan-larangan Allah tidak ada yang melanggarnya dan menjaga hak-hak hamba-Nya agar tidak hilang binasa.

5. Menjaga perbatasan negara dengan perangkat yang memadai dan kekuatan yang dapat mempertahankan negara sehingga musuh-musuh negara tidak dapat menyerang negara Islam dan tidak menembus pertahanannya serta tidak dapat mencelakakan kaum muslimin atau kalangan kafir mu'ahad (yang diikat janjinya).

6. Berjihad melawan pihak yang menentang Islam setelah disampaikan dakwah kepadanya hingga ia masuk Islam atau masuk dalam jaminan Islam atau dzimmah. Dengan demikian, usaha untuk menjunjung tinggi agama Allah di atas agama-agama seluruhnya dapat diwujudkan

7. Menarik fai-i (hasil rampasan)dan memungut zakat sesuai dengan ketentuan yang telah ditetapkan oleh syarie at Islam secara jelas dalam nash dan ijtihad.

8. Mengatur penggunaan harta baitul-maalsecara efektif, tanpa berlebihan atau kekurangan, dan memberikannya pada waktunya, tidak lebih dahulu dari waktunya dan tidak pula menundanya hingga lewat dari waktunya.

9. Mengangkat pejabat-pejabat yang terpercaya dan mengangkat orang-orang yang kompeten untuk membantunya dalam menunaikan amanah dan wewenang yang ia pegang dan mengatur harta yang berada di bawah wewenangnya, sehingga tugas-tugas dapat dikerjakan dengan sempurna dan harta negara terjaga dalam pengaturan orangorang yang tepercaya.

10. Agar ia melakukan sendiri inspeksi atas pekerjaan para pembantunya dan meneliti jalannya proyek sehingga ia dapat melakukan kebijakan politik umat Islam dengan baik dan menjaga negara. la tidak boleh menyerahkan tugas ini kepada orang lain 
karena sibuk menikmati kelezatan atau beribadah, karena orang yang terpercaya dapat saja menjadi pengkhianat dan orang yang baik dapat saja berubah menjadi penipu. ${ }^{20}$

\section{Unsur-unsur Jarimah Al-Baghyu}

Dalam tindak pidana pemberontakan terdapat tiga rukun penting, yaitu :

\section{a. Memberontak terhadap pemimpin negara yang sah dan berdaulat}

Maksudnya adalah upaya untuk memberhentikan pemimpin negara dan jabatannya. Para pemberontak tidak mau mematuhi undang-undang yang sah dan tidak mau menunaikan kewajiban mereka sebagai warga negara.

Namun demikian, para ulama fiqh menyatakan bahwa pemberontakan yang muncul karena pemerintah mengarahkan warganya untuk berbuat maksiat tidak dapat dinamakan al-baghyu. Alasan ulama adalah sabda Rasulullah SAW berikut :

Dari Umar RA dari Nabi SAW beliau bersabda,"Mendengar dan menaati pemimpin hukumnya haq (wajib) selama tidak memerintahkan kemaksiatan. Jika diperintah untuk melakukan kemaksiatan, tidak wajib mendengar dan menaati”. (HR. Al-Bukhari) ${ }^{21}$

\section{b. Dilakukan secara demonstratif}

Maksudnya adalah di dukung oleh kekuatan bersenjata. Oleh sebab itu menurut ulama fiqh, sikap sekadar menolak kepala negara yang telah diangkat secara aklamasi, tidak dinamakan al-baghyu. Misalnya, sikap Ali bin Abi Thalib yang tidak mau membaiat Abu Bakar atau sikap Ibnu Umar dan Abdullah bin Zubair yang tidak mengakui keabsahan pemerintahan Yazid bin Mu'awiyah. Sikap mereka tidak termasuk al-baghyu karena sikap mereka tidak demonstratif.

Contoh lain adalah golongan khawarij yang ada pada masa pemerintahan Khalifah Ali bin Abi Thalib. Mengenai hal ini, Imam Al-Syafi'i mengatakan, “sesungguhnya sekelompok orang yang menampakkan sikap seperti kaum Khawarij dengan memisahkan diri dari jama'ah, bahkan menganggap jama'ah tersebut kafir, tidak menyebabkan diperbolehkannya memerangi kelompok ini sebab mereka masih berada dibawah perlindungan Iman. Hal tersebut tidak menjadikan mereka berubah status menjadi (murtad) yang Allah SAW perintahkan untuk diperangi. ${ }^{22}$

20 http://eprints.walisongo.ac.id/6809/3/BAB II.pdf Jurnal M.Fatkhimuna.2016, diakses tanggal 5 Desember 2019

21 Nurul Irfan, Op Cit, hlm 62

22 Ibid, hlm 68 


\section{c. Termasuk perbuatan pidana}

Maksudnya adalah usaha untuk menggulingkan pemerintahan yang sah dan berdaulat dengan cara mengacau ketertiban umum. Apabila tindakan pelaku itu tidak menjurus pada penggulingan pemerintahan dan tidak pula melakukan tindak pidana (seprerti mebunuh, merampas, memperkosa, dan merampok), maka ulama fiqh menyatakan bahwa itu tidak termasuk al-baghyu. ${ }^{23}$

\section{Hukuman Terhadap Pemberontak}

Suatu gerakan anti pemerintah dinyatakan pemberontak dan harus dihukum sebagaimana yang ditetapkan pada garis hukum. ${ }^{24}$ Yaitu pembalasan terhadap orang-orang yang memerangi Allah dan Rasul-Nya dan membuat kerusakan di muka bumi adalah dibunuh atau disalib (dipotong tangan dan kaki mereka dengan bertimbal balik) atau dibuang dari negeri tempat kediamaannya. Sanksi hukum tersebut sebagai suatu penghinaan untuk mereka di dunia dan di akhirat memperoleh siksaan yang besar.

Penerapan hukum dimaksud akan dilaksanakan bila memenuhi persyaratan sebagai berikut:

1. Pemegang kekuasaan yang sah bersikap adil dalam menetapkan kebijakan. ${ }^{25}$

2. Pemberontak merupakan suatu kelompok yang memiliki kekuatan.

3. Dari gerakan tersebut diperoleh bukti-bukti kuat yang menunjukkan sebagai gerakan untuk memberontak guna menggulingkan pemerintahan yang sah. Jika tidak gerakan tersebut dikategorikan sebagai pengacau keamanan atau perampok.

4. Gerakan tersebut mempunyai sistem kepemimpinan, karena tanpa ada seorang pemimpin tidak mungkin kekuatan akan terwujud.

Sanksi hukum bagi pelaku tindak pidana pemberontakan adalah hukuman mati, sebagaimana dijelaskan dalam Al-quran dan hadis Rasulullah SAW, antara lain:

1. Qs. Al-Hujurat:9

"Dan kalau ada dua golongan dari mereka yang beriman itu berperang hendaklah kamu damaikan antara keduanya. Akan tetapi, kalau yang satu melanggar perjanjian terhadap yang lain, hendaklah yang melanggar perjanjian itu kamu perangi sampai sampai surut kembali pada perintah Allah. Kalau ia telah surut, damaikanlah antara

23 Ibid, hlm 71

24 Zainuddin Ali, Hukum Pidana Islam, Jakarta: Sinar Grafika, 2012, hlm 76

25 Ibid 
keduanya menurut keadilan, dan hendaklah kamu berlaku adil; sesungguhnya Allah mencintai orang-orang yang berlaku adil.” (QS. Al-Hujurat (49):9

2. Hadis "dari Aisyah r.a., ia berkata: "barangsiapa memecah belah persatuan kaum muslimin padahal ia telah sepakat untuk memilih satu pemimpin dengan maksud menceraikan umat, maka bunuhlah ia"

3. "barangsiapa yang mendatangimu, sedangkan urusanmu berada ditangan mereka (pemimpin mereka) dan mereka ingin merusak kekuasaanmu serta akan memorakmorandakan jemaahmu, maka bunuhlah mereka" (HR. Muslim)

4. Dari Abdullah bin Amru bin Ash, ia berkata, Rasulullah SAW bersabda: "barangsiapa membaiat seorang imam (pemimpin) dn memberikan telapak tangan dan buah hatinya (ketaatannya) kepada,maka hendaklah ia menaatinya jika ia dapat. Kemudian jika datang orang lain merebutnya, maka penggallah leher orang lain itu”(HR. Muslim)

5. "Dari Zaid bin /alaqah, ia berkata: saya mendengar Arfajah berkata: saya mendengar Rasulullah SAW bersabda: "Sesungguhnya nanti terjadi banyak fitnah. Oleh karena itu barangsiapa yang mau memecah urusan (persatuan) umat ini padahal mereka itu bersatu, maka penggallah ia (lehernya) dengan pedang, siapapun mereka" (HR. Muslim)

Sedangkan peraturan makar yang merupakan Kejahatan yang mengancam kepentingan hukum atas keamanan dan keselamatan di Negara Republik Indonesia sebagaimana dimuat dalam Bab I Buku II KUHP terdiri dari 3 bentuk, ${ }^{26}$ yaitu:

1. Pasal 104 yaitu makar yang menyerang terhadap kepentingan hukum bagi keamanan Kepala Negara atau wakilnya.

2. Pasal 106 yaitu makar yang menyerang terhadap kepentingan hukum bagi keutuhan wilayah Negara.

3. Pasal 107 yaitu makar yang menyerang terhadap kepentingan hukum bagi tegaknya pemerintahan Negara.

\section{Pertanggung Jawaban Pidana dan Perdata Pelaku Jarimah Al-Baghyu}

Pemisahan pertanggungjawaban pidana dan perdata bagi pelaku tindak pidana albaghyu berkaitan dengan waktu terjadinya jarimah ini, yaitu sebelum serta sesudah terjadi pemberontakan dan pada saat terjadi pemberontakan. ${ }^{27}$

26 Chazawi, Adami, Kejahatan Terhadap Keamanan dan Keselamatan Negara, Jakarta: Raja Grafindo Persada. 2002, hlm 11

27 https://kingilmu.blogspot.com/2015/08/fiqh-jinayah-pengertian-unsur-dan-hukum.html , diakses tanggal 5 Desember 2019 


\section{a. Pertanggungjawaban sebelum dan sesudah terjadinya pemberontakan}

Seluruh tindakan pemberontakan yang bersifat pidana dan perdata yang mereka lakukan sebelum dan sesudah pemberontakan wajib mereka pertanggungjawabkan. Apabila mereka melakukan pembunuhan, pencurian dan pemerkosaan mereka harus dikenakan sanksi pidana sesuai dengan jarimah yang mereka lakukan.

\section{b. Pertanggungjawaban pada saat terjadi pemberontakan}

Ulama' mazhab 4 bersepakat bahwa pemberontakan yang memiliki argumentasi yang kuat, tidak berkewajiban mengganti harta dan jiwa yang terbunuh ketika terjadi kontak senjata.

\section{E. Kesimpulan}

Dapat disimpulkan bahwa tindakan makar yang diatur dalam kitab undang-undang hukum pidana dan termasuk dalam jarimah al-baghyu dalam hukum pidana Islam merupakan tindakan yang menyalahi aturan dan melaggar ketentuan karena orang yang melakukan tindakan perlawanan terhadap pemerintah yang sah berarti sama dengan orang yang melawan ketentuan allah SWT. Maka sesuai Al-Quran dan hadis orang tersebut harus di hukum dengan hukuman mati tetapi tetap dengan pertimbangan-pertimbangan yang sesuai ketentuan yang terdapat dalam Al-Quran, Hadis dan sumber-sumber hukum pidana islam lainnya.

\section{DAFTAR PUSTAKA}

\section{BUKU :}

Al-Quran dan Hadis

Kitab Undang-udang Hukum Pidana

A. Hasjmy, 1984, Di Mana Letaknya Negara Islam, Surabaya: Bina Ilmu,

Hasan al-Banna, 1986, Majmu'ah Rasa'il al-Imam Syahid Hasan al-Banna, alih bahasa, Su'adi Sa'ad, "Konsep Pembaruan Masyarakat Islam", Jakarta: Media Da'wah

Nurul Irvan, Masyrofah. 2013, Fiqh Jinayah, jakarta: Amzah,

Mardani, 2019, Hukum Pidana islam,Jakarta:Kencana,

Asadullah al-Faruq, 2009 Cet. Ke-1,Hukum Pidana dalam Sistem Hukum Islam. Bogor: Ghalia Indonesia 
Mustofa dan Beni Ahmad Saebani, 2013, Hukum Pidana Islam: Fiqh Jinayah, Bandung: Pustaka Setia

Rahmat hakim, 2000, hukum pidana islam (fiqh jinayah), Bandung; Pustaka setia,

Zainuddin Ali, 2012, Hukum Pidana Islam, Jakarta: Sinar Grafika,

Chazawi, Adami, 2002, Kejahatan Terhadap Keamanan dan Keselamatan Negara, Jakarta: Raja Grafindo Persada.

\section{INTERNET}

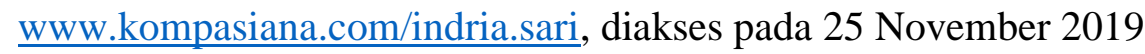

https://kingilmu.blogspot.com/2015/08/fiqh-jinayah-pengertian-unsur-dan-hukum.html. diakses pada 24 November 2019

http://eprints.walisongo.ac.id/6809/3/BAB II.pdf Jurnal M.Fatkhimuna.2016. diakses pada 23 November 2019 